\title{
Caregiver experiences, attitudes and perceptions about feeding toddlers and preschool children in Switzerland: a qualitative study
}

Emma F. Jacquier ${ }^{1,2^{*}}$, Anthony Gatrell ${ }^{1}$ and Amanda Bingley ${ }^{1}$

\begin{abstract}
Background: Young children depend upon caregivers to make healthy food and beverage choices on their behalf. Research to understand caregiver perspectives may help develop interventions to improve diets and offer new insights for healthcare professionals and future nutrition studies. The main study aim was to explore caregiver feeding experiences, with a focus on portion sizes and attitudes towards beverages, for the first time in Switzerland, and contribute to the European perspective in this field.

Methods: Inductive, qualitative study with purposive sampling of 19 male and female caregivers (low-high income, 20-46y) of children (1-5y) using in-depth interviews. The model, "Food Choice Process over the Life Course", was used as a theoretical framework. Full transcripts underwent a thematic analysis. Key themes were developed from the data.

Results: Key themes were a) Rules and routines b) Tacit knowledge c) Explicit knowledge d) Managing. Rules about foods and beverages to encourage/limit were widespread. Participants struggled to explain how they portioned foods but offered volume-estimates of beverages portions. Perceptions about health effects of beverages influenced choices. Managing time and budget influenced purchases and meal preparation. There was good agreement with the theoretical framework.

Conclusions: Rules and routines reflected anti-obesity recommendations and food-choice values. Perceived health effects of certain beverages, cultural classifications of snacking and the influence of income and time highlight multi-level determinants influencing dietary choices about feeding young children. Health-care professionals may wish to consider these emergent themes when advising on early-childhood feeding. Future studies are required to understand more about the attitudes and perceptions of beverages in the diets of toddlers and preschooler, along with perceptions related to snacking behaviours.
\end{abstract}

Keywords: Nutrition, Feeding, Preschool, Diet, Young children, Switzerland

\footnotetext{
* Correspondence: emma.jacquier@rd.nestle.com

${ }^{1}$ Faculty of Health and Medicine, Lancaster University, Bailrigg, Lancaster LA1 4YW, UK

${ }^{2}$ Nestle Nutrition, 12 Vreeland Road, Florham Park, NJ 07932, USA
} 


\section{Background}

Research designed to understand the caregiver feeding experience is important, particularly in the years before children go to school Young children depend on their caregivers to make choices about the types foods and beverages offered, when they are offered, the number and size of portions and if the eating experience is pleasurable or otherwise [1,2]. Dietary behaviours and food preferences develop in early life [3] and have been shown to affect consumption habits [4]. Improvements in the diets of toddlers and preschool children will, therefore, depend upon improved caregiver choices. However, there is surprisingly little research on the processes that caregivers go through when determining what, and how much, food and drink to provide to very young children, and the caregiver attitudes and perceptions related to the feeding experience. Qualitative research designed to understand the caregiver experience when feeding very young children may go towards designing future studies, interventions, or healthcareprofessional (HCP) led support, which could lead to improvements in food intake, diets and the caregiverchild feeding-experience. In addition, qualitative studies such as this may help HCPs to understand how objective feeding advice is subjectively integrated into everyday life.

European [5] and Swiss national recommendations [6] aimed at improvement of diet quality and prevention of childhood obesity recommend encouraging regular meals, increasing fruit and vegetable consumption, limiting, or completely avoiding sugar-sweetened beverage consumption (SSB) consumption, and providing water as a beverage of choice. However, it is not known to what extent dietary guidelines are translated into the feeding goals of caregivers, particularly in Switzerland, where this research took place.

Concerning excess energy intake and food quantities, prior data indicate that larger food portions may lead to increased intakes $[7,8]$. Indeed, limiting children's portion sizes may be a useful strategy to limit excess energy intake. However, in general, adults have been shown not to be very good estimators of portion size [9]. When determining portion sizes for preschool children, adults report using the size of the plate, or an estimation of the child's appetite as guide to how much food to serve $[10,11]$. However, there is surprisingly little research on the considerations that influence the portion sizes offered by caregivers, as well as strategies that caregivers may use to manage portion sizes.

Beverage portion sizes are of relevance since overconsumption of SSBs has been associated with excess weight gain in preschool, school-aged children and adults has led public health authorities, including those in Switzerland, to make recommendations to reduce SSB consumption [12-14]. How caregivers determine beverage portion sizes, and caregiver attitudes towards fitting beverages into the diets of very young children has not been widely studied outside of the U.S. [15-17].

The goal of this qualitative study was to engage Swiss caregivers in an in-depth discussion about their experiences, attitudes and perceptions about feeding toddlers and preschool children, with an emphasis on how caregivers determine the portion sizes of foods and beverages, and their attitudes towards beverages into the diet. The term attitude is used throughout as meaning the opinions and feelings of participants as recounted in the interview transcripts. The term perception is used to mean how the participants think about feeding young children, their beliefs and what they understand or do not understand.

\section{Methods \\ Methodological approach, research paradigm and theoretical framework}

The ontological stance of this research is a constructivist perspective. It assumes an interactive relationship between the researcher, and the participant and aims to reconstruct participants' accounts towards a consensus [18]. It is, therefore, compatible with qualitative research methods. The Food Choice Process Model $[19,20]$ was used as a theoretical framework in this study and is consistent with the research paradigm.

\section{Study population and sampling}

To be consistent with the epistemological underpinnings of this study, participants were purposively sampled to vary in age, gender and income backgrounds, and to provide information pertinent to the study [21]. A national database of landline numbers was used to recruit participants by telephone (Link Qualitative AG, Lausanne). Participants were eligible to take part in the study if they were the principle caregiver of a healthy toddler or preschooler aged between 1-5y and were responsible for providing all foods and drinks on most days of the week. In addition participants were screened to ensure that they did not work in a field related to childhood health/nutrition and had not previously participated in research on the topic. Potential participants were taken through a screening questionnaire to gather demographic data and to check their eligibility for participation.

\section{Ethics, consent and permissions}

Ethical approval for this research was obtained from the Faculty of Health and Medicine Research Ethics Committee of the University of Lancaster, U.K. (November, 
2013). However, no formal ethical approval was required for such a study in Switzerland.

\section{Interviews}

An in-depth interview schedule of leading questions was developed based upon the Child Feeding Questionnaire [22] starting with questions used by Sherry et al. [11] in qualitative research with caregivers of preschool children. It was adapted to include opening questions about typical meal, snack and beverage pattern in a $24 \mathrm{~h}$ period. It also included a section focusing specifically on beverages. The interview guide was developed in French and pilot-tested with three caregivers to ensure the questions were clear and comprehensible. Interviews were conducted in the homes of participants, during March and April, 2014, lasting approximately $60 \mathrm{~min}$. Seventeen interviews were conducted. However, 2 male participants were spontaneously joined by their wives, resulting in a participant sample size of $n=19$. Interviews were conducted until saturation was reached. Saturation was determined by the repetition of themes, with no new themes appearing, offering no new coding opportunities. All interviews were digitally recorded and field notes were taken during the interviews.

\section{Questions}

Interviews commenced by asking participants to describe meals and in-between-meal eating and drinking occasions on a typical day of the week, including examples of the types of foods and beverages consumed. Questions followed about their experience of feeding at mealtimes and the goals of mealtimes; their experience of foods and beverages consumed in-between meals; how they make choices about the types of foods and beverages to feed their children; how they decide upon the quantity of food and beverages to feed their children and how they decide which beverages to provide, and how to portion them.

\section{Analysis}

All recorded interview material was transcribed verbatim, into English, by a professional transcriber. Thematic Analysis (TA) was used for data analysis. TA can be applied to a wide range of theoretical frameworks [23] and was applied in an inductive manner ("bottom-up") guided by the six-phase process described by Braun and Clarke [23]. The coding was led by one author (EJ). Two authors $(\mathrm{AG}, \mathrm{AB})$ oversaw the process and reviewed the quality of the analytical phase. The six-phase approach consists of familiarisation with the data, coding the data, searching for themes, reviewing themes, defining and naming themes, and refinement of the analytical narrative. Coding followed an inductive approach with the identified themes being strongly linked to the data themselves. Coding units were cross-checked against the theoretical framework and similarities and differences were noted. Saturation was reached with no adaptation of the coding system required for later interviews. Central organising concepts were identified in order to construct key, overarching themes [21]. AtlasTi was used to electronically review, code, and catalogue the transcripts as analysis moved through the six phases.

\section{Results}

\section{Participants}

After providing informed consent, 19 participants, aged $20-46 y$ (mean age $=36 y$ ) took part in the study. All resided in the Canton Vaud, in the Lausanne region of Switzerland. Caregivers either worked part-time $(n=11)$ or full-time $(n=4)$ or did not work $(n=2)$ (Table 1$)$.

Emergent themes were placed in categories labelled; a) Rules and routines b) Tacit knowledge c) Explicit knowledge and d) Managing. These major themes and relevant sub-themes are presented and discussed.

\section{Rules and routines}

When asked how to decide which foods and beverages to offer, rules and routines were recounted by all but two participants. Rules were specific principles, sometimes rigid, sometimes more flexible, that governed intake of foods, beverages and certain feeding practices. Routines were regular, unvarying, habitual acts in the feeding process, carried out on a daily basis,

Table 1 Characteristics of the participants

\begin{tabular}{lll}
\hline Characteristics of the participants $(n=19)$ & Mother & 15 \\
\hline Caregiver & Father & 3 \\
& Child-minder & 1 \\
& Married & 12 \\
& Living with partner & 5 \\
Marital status & Divorced, no partner & 2 \\
& Low & 7 \\
Income & Middle & 6 \\
& High & 6 \\
Education & Finished school & 6 \\
& Finished college & 2 \\
Number of children in the family & Finished University & 11 \\
& 1 child & 5 \\
& 2 children & 10 \\
Ages of the children & $>2$ children & 2 \\
& $1 y-<2 y$ & 5 \\
& $2 y-<5 y$ & 18 \\
\hline
\end{tabular}


sometimes at the same time each day. The most frequently cited rules were in relation to encouraging the consumption of fruits and vegetables, practicing balanced, varied eating, limiting sweet foods and "fizzy drinks". Some participants said they restricted all sweet foods. However, some participants cited flexible rules related to moderating the consumption of sweet foods (Table 2).

Half of the participants encouraged the child to finish their entire meal. Some caregivers rewarded children with desserts if they finished their meal. However, the remaining participants allowed children to self-regulate their food intake at meals. Rules and routines about eating in between meals followed culturally acceptable routines in Switzerland; namely the feeding of children at $10 \mathrm{am}$ and $4 \mathrm{pm}$. However, when asked about snacking, the practice was largely refuted, or, associated with a particular subset of foods such as salty and sweet snackfoods.

\section{Food and beverage portion sizes}

All participants, without exception, found it difficult to express how they judged food portion sizes. Participants made reference to serving what they anticipated that the child would be able to finish, based upon their usual experience, or, their perception of the child's appetite. Alternatively, portions were provided according to the size of the plate (Table 3).

Contrary to food portion sizes, when asked about beverage portion sizes, all participants gave examples of approximate volumes that the child was served and commented on the typical volumes habitually consumed.
All participants described learnt facts in relation to the health effects of milk, juice and water. Milk was provided by all caregivers in the morning and evening. However, water was cited as the most important beverage in children's diets. Several participants described how orange juice was provided when children were constipated based upon advice from healthcare professionals (Table 4).

\section{Managing}

Cooking meals at home was discussed by almost all participants. Some caregivers cited time as a constraint to meal preparation. Whereas other caregivers linked cooking to saving them time. Caregivers that cooked were able to describe recipes they used to help increase children's vegetable consumption. Preparing homemade food was also perceived to be better for health than using commercially prepared meals due to the participant's knowledge of the ingredients. The family budget was described to influence the quality and frequency of foods offered. A small number of high- income caregivers said that they did not pay attention to their budget when buying groceries. Some low-income participants described clever strategies that they employed such as buying small amounts of more expensive, nutrient-dense foods, for the children alone (Table 5).

\section{Discussion}

The accounts of the participants in this study provide nuanced insights which could help inform obesity prevention initiatives and highlight where caregivers many benefit from educational and practical support.

Table 2 Rules and routines

\begin{tabular}{|c|c|}
\hline Emerging theme: & Quote \\
\hline Fruit and vegetable consumption & $\begin{array}{l}\text { "I always try to make sure they have at least one type of vegetable at every meal." } \\
\text { "He needs to have at least one vegetable per day anyway, that's for sure." }\end{array}$ \\
\hline Balanced meals & "I try to make it varied every day. Every time I'll include protein, vegetables and carbohydrates." \\
\hline Consumption of/access to sweet foods & $\begin{array}{l}\text { Strict } \\
\text { "They don't have candy...I don't buy it, when they do have candy, it's because somebody gave } \\
\text { them a bag. So I hide it." } \\
\text { Flexible } \\
\text { "Desserts? Yes, yes. It can be chocolate, it can be fruit, a little cake. We have limits, too, of course } \\
\text { they eat chocolate, but in moderation." }\end{array}$ \\
\hline No fizzy drinks & $\begin{array}{l}\text { "I won't encourage fizzy drinks at all. Fruit juice. I think, that's all." } \\
\text { "First I don't think it's good because it's fizzy... fizzy drinks are not really superb for our stomachs." }\end{array}$ \\
\hline Finish (or not) the meal & $\begin{array}{l}\text { Strict } \\
\text { "It turns into a fight and she screams because she doesn't want to accept the rules... I try to make } \\
\text { her eat. I tell her off, I am severe and I bang my fist on the table so that she finishes her plate." } \\
\text { Flexible } \\
\text { "If they're hungry they eat, if not, it doesn't matter. I always have a hard time pushing her because } \\
\text { my parents pushed me". }\end{array}$ \\
\hline We don't snack & $\begin{array}{l}\text { Participant: "There is no snacking." } \\
\text { Interviewer: "But are they ever hungry sometimes between meals?" } \\
\text { Participant: "It can happen but they must wait for the four o'clock." }\end{array}$ \\
\hline
\end{tabular}


Table 3 Tacit knowledge

\begin{tabular}{ll}
\hline Emerging theme: & Quote \\
\hline "I just dish" & "I can't explain why I put these quantities on \\
the plate. & "Honestly I don't know, I have no idea. I dish, \\
I think to myself, a little bit of everything and \\
that's it... I just dish." \\
"It's guesswork." \\
"I would say that we think that he should be \\
able to eat the amount of a small plate." \\
"Let's say that we put children's portions, \\
to fit their plates." \\
"I know more or less how much he is capable \\
of eating, how much he eats every day on \\
average." \\
"Well I know about how much they eat, so I'm \\
going to prepare a portion accordingly... I insist \\
they eat at least what I think they can."
\end{tabular}

\section{Rules and routines may influence feeding goals and behaviours}

Rules and routines were positive in their intention and reflected both European and national-level anti-obesity and healthy-eating messages [5, 6] such as encouraging regular meals, increasing fruit and vegetable consumption, limiting, or completely avoiding SSB consumption, and providing water as a beverage of choice. The setting of limits in relation to foods perceived to be unhealthy is consistent with findings from qualitative studies with caregivers of young children in the U.S., U.K. and Australia [24-26]. Nonetheless, despite displaying knowledge about good dietary behaviours, studies indicate that dietary guidelines are poorly adhered to by both adults and children in Switzerland [27, 28]. Therefore the description of rules and routines may indicate feeding goals but may not reflect actual consumption behaviours. Further research is required to understand if actual food and beverage intake patterns reflect caregiver feeding goals.

Table 4 Explicit knowledge

\begin{tabular}{|c|c|}
\hline Emerging theme: & Quote \\
\hline Volume estimates & $\begin{array}{l}\text { "She likes tea, perhaps ... } 300 \text { or } 400 \text { ml." } \\
\text { "I would say around } 150 \text { millilitres [of milk]. } \\
\text { Yes, between } 100 \text { and } 150 \text { millilitres." } \\
\text { "I would say } 600 \text { to } 700 \text { millilitres [of water]. } \\
\text { Yes, about } 700 \text { millilitres." } \\
\text { "It's about } 250 \text { millilitres [of milk] when I look } \\
\text { at the little one's bottle, yes. And at least three } \\
\text { decilitres of water." }\end{array}$ \\
\hline $\begin{array}{l}\text { Health effects of } \\
\text { beverages }\end{array}$ & $\begin{array}{l}\text { "For me, milk it's about the dairy intake in terms } \\
\text { of calcium. Everything in milk that helps growth." } \\
\text { "I give [orange juice] to him because sometimes he } \\
\text { has problems doing a number two, for fibre..." } \\
\text { "Water...we know that water is the best of drinks, } \\
\text { in relation to all that is found in certain studies } \\
\text { regarding what it brings...". }\end{array}$ \\
\hline
\end{tabular}

As described in the theoretical framework, rules and routines may originate through caregivers attempts to standardise the recurrent situation of meals and snacks using a classification system that can be cultural, social, or personal [29, 30]. For example, eating in-between meals was perceived negatively, but the cultural practice of feeding children in Switzerland at 10 am and $4 \mathrm{pm}$ was not perceived as snacking per se. Participants described snacking as involving certain salty snacks or sweet foods. This indicates that the conceptualisation of snacking by the researcher and the participant may be different, or have cultural specificities. This requires further understanding since it may impact how HCP advice is delivered along with impacting the collection of dietary intake data.

Portioning foods vs. beverages: the tacit and the explicit Caregivers were unsure how to provide appropriate food-portion sizes and had difficulty to explain how they estimated the appropriate food-portion size. Participants exclaimed they did not need further support/education about portion sizes. Tacit knowledge is commonly defined as that which cannot be explicated, whereas explicit knowledge follows rules and steps, and can be written down and described [31]. The use of tacit knowledge in estimating preschool children's food portion sizes has not been previously reported in Switzerland, but has been described in studies from the U.S. Johnson et al. [32] reported two key themes about how mothers portioned meals for their children in the home-setting; (1) portion sizes differ for children who are "good" eaters and "picky" eaters; (2) mothers know the "right amounts" to serve their child. The present study supports the findings in (1) and (2). This study also agrees with previous qualitative work from the UK amongst caregivers who reported that they fed their children the amount they thought the children could eat, based on their perception of the child's individual appetite [10, 25].

A novel finding of this study is that contrary to the description of preparing food portions, participants were able to precisely describe beverage portions, even as far as providing volume estimates for the amounts of water, tea, juice and milk consumed. This attention to the volume of liquids consumed in the early years of the child's life-along with the fact that drinking vessels contain a scale for the estimation of volume-may be a means in which the caregiver becomes more attuned to the quantities of liquids served and consumed. This may suggest that major life events, such as having a child, may impact expertise in relation to the portioning of liquids. This is also consistent with the theoretical framework whereby Sobal et al. [30] describe the impact of major life events on the feeding behaviours. This hypothesis 
Table 5 Managing

\begin{tabular}{|c|c|}
\hline $\begin{array}{l}\text { Emerging } \\
\text { theme: }\end{array}$ & Quote \\
\hline Time to cook & $\begin{array}{l}\text { "I buy ready-made foods less and less, because I have } \\
\text { more and more time to cook." } \\
\text { "Ideally, I would take time to cook all the meals for } \\
\text { them... But I work and I don't always have time." }\end{array}$ \\
\hline $\begin{array}{l}\text { Homemade is } \\
\text { better }\end{array}$ & $\begin{array}{l}\text { "There are things that are quick and easy to do, and are } \\
\text { also good for the health. Why should I use something } \\
\text { which has already been prepared, I don't really know } \\
\text { what is in it, because I'm not the one who prepared it." }\end{array}$ \\
\hline Budget & $\begin{array}{l}\text { "Now, we look at the price first." } \\
\text { "Yes, it's expensive. Especially meat, steaks. I never buy } \\
\text { that... but I buy it for her only. I can buy } 100 \text { grams or } \\
200 \text { grams for her." }\end{array}$ \\
\hline
\end{tabular}

would require further research and may have impact for the collection of dietary intake data.

\section{Explicit knowledge about health effects of beverages}

Despite milk being consumed morning and evening by all participants, and the health benefits of milk being widely described, caregivers perceived water to be the healthiest of all beverages. This would be in agreement with public health nutrition advice in Switzerland to offer water in preference to sweetened beverages, especially when feeding young children [6, 14]. Several participants' subjectively integrated advice of HCPs in providing fruit juice-specifically orange juice-when their child experienced constipation. A search of the literature failed to find any studies which reference this notion, nor paediatric guideline, to support this recommendation [33]. If such a recommendation has no scientific basis, then there is scope to educate HCPs. Sweetened beverages were limited, by the caregiver, if they contained "fizz" (i.e. carbonated beverages) but fruit juice was not perceived as a sweetened beverage that should be limited. Rather, the "fizziness" itself was perceived as being unhealthy. This has been reported in a previous study in Switzerland in older children and adults [34] and indicates opportunity to educate caregivers about the nature and composition of sugar sweetened beverages and their moderation in the diets of toddlers and preschoolers.

\section{Challenges in the provision of foods and beverages}

Participants described three sub- themes which impacted their ability to manage the provision of foods and beverages of their choosing, in the manner of their choosing; 1) Time to cook 2) Homemade is better and 3) Budget.

Most participants expressed issues in finding time for planning and preparing meals. This is comparable to findings from the US in which families of employed mothers have less frequent family meals, more frequent fast food for family meals, and spend less time on food preparation [35]. There may be scope to include "available time" as a factor in the development of healthy eating guidelines and in advice from HCPs.

Several participants preferred homemade food and rejected commercially produced meals. Negative attitudes towards commercially prepared meals have been reported in previous European studies [36, 37]. Homemade food has been thought of as an authentic creation of the family, and a way for the family to create meaning and identity [38]. Therefore, regardless of the nutritional quality of a meal, homemade food may be linked to creation of family identity and meaning and be the preferred option for feeding young children. Caregivers may benefit from advice on how to prepare quick, healthy, age-appropriate, family meals.

With the exception of 3 participants, all caregivers described shopping according to a budget often buying lower quality items, for example meats, due to the cost constraints. Cost can be a barrier to a high-quality, nutrient-dense and varied diet [39]. As described by one low-income participant, households may experience periods whereby the acquisition of nutrient-dense foods may not be possible for the entire family. The extent to which periods of food insecurity may occur amongst low-income families in Switzerland is not known. Recent studies in Switzerland describe how low-cost food items are comparable in nutrient composition to more costly branded items [40] but available product choice of lowcost food items is sometimes limited. The feasibility of access to a healthy diet, for low-income families in Switzerland, remains under-researched.

A qualitative study, such as this, can help to improve understanding in a way that randomized controlled trials cannot. As usual, in qualitative research, the purposively selected participants are not expected to be representative of all caregivers in Switzerland. However, this study provides an explorative overview of the caregiver experiences when feeding very young children, and makes a novel contribution to Swiss and European qualitative research in nutrition. Future research is required to confirm the study findings herein.

\section{Conclusion}

The qualitative themes discussed in this study may inform future research and support HCPs when advising on diet and nutrition. HCPs may wish to consider the feeding goals of caregivers and balance advice with awareness of the difficulties in preparing appropriate food portion sizes along with an appreciation of the caregiver's available time and potential budget constraints. HCPs may also wish to discuss the nutritional quality of foods and beverages, especially those consumed in-between meals. Further research is required to develop interventions to support selection of nutrientdense foods, meal-planning, budgeting and time-saving 
tips, in particular for those on a low income. There is also a need for further research into caregiver conceptualisation of snacking and the implications it may have for the definition of "snacking" in nutrition research and the collection of dietary intake data.

\section{Abbreviations}

COREQ: Consolidated criteria for reporting qualitative research: HCP: Healthcare professional; SSB: Sugar-sweetened beverage; TA: Thematic analysis; U.K.: United Kingdom; U.S.: United States; Y: Year

\section{Acknowledgements}

The author thanks Dr. Klazine van der Horst for quidance and Link Qualitative AG for technical support. Portions of this study have been presented in abstract form at the meeting of the American Society of Nutrition, San Diego, April 2016.

\section{Funding}

This research was undertaken as part of Emma Jacquier's PhD thesis as a registered student with Lancaster University, UK. The research was sponsored by Nestec S.A and conducted in Lausanne, Switzerland.

\section{Availability of data and materials}

Data files and materials from this study will be made publically available following the assessment and award of the PhD thesis upon which this manuscript is based. At that time, data will be deposited in a suitable Lancaster University database, or appropriate national archive.

\section{Authors' contributions}

EJ conceived the research idea and study design. EJ collected, analysed, interpreted the data and prepared the manuscript. $A G$ and $A B$ provided guidance throughout the study. All authors read and approved the final manuscript.

\section{Competing interests}

Emma Jacquier was a PhD candidate and a Nestle Research employee (Nestec S.A.). This research was funded by Nestec S.A., Vevey, Switzerland The opinions expressed are those of the authors and do not necessarily represent the views or recommendations of the respective affiliations. The authors declare that they have no competing interests.

\section{Consent for publication}

All participants were informed verbally about the study aim, protocol and future publication in the scientific literature. Informed consent was provided in written and verbal formats and digitally recorded. All information was treated confidentially. The consolidated criteria for reporting qualitative research (COREQ) was used to organise and report results [41].

\section{Ethical approval and consent to participate}

Ethical approval for this research was obtained from the Faculty of Health and Medicine Research Ethics Committee of the University of Lancaster, UK (November, 2013). Ethical approval was not required for a study design of this nature in Switzerland [42]

\section{Received: 5 May 2016 Accepted: 30 August 2016}

Published online: 20 September 2016

\section{References}

1. Ventura AK, Birch LL. Does parenting affect children's eating and weight status? Int I Behav Nutr Phys Act. 2008;5(1):1-12.

2. May AL, Dietz WH. The feeding infants and toddlers study 2008: opportunities to assess parental, cultural, and environmental influences on dietary behaviors and obesity prevention among young children. J Am Diet Assoc. 2010;110 Suppl 12:S11-5.

3. Birch LL. Development of food preferences. Annu Rev Nutr. 1999:19(1):41-62.

4. Skinner JD, et al. Children's food preferences: a longitudinal analysis. J Am Diet Assoc. 2002:102(11):1638-47.

5. Agostoni $\mathrm{C}$, et al. Role of dietary factors and food habits in the development of childhood obesity: a commentary by the ESPGHAN committee on nutrition. J Pediatr Gastroenterol Nutr. 2011;52(6):662-9.
6. Walter $P$, Infanger $E$, Mühlemann P. Food pyramid of the Swiss Society for Nutrition. Ann Nutr Metab. 2007:51 Suppl 2:15-20.

7. Fisher JO, et al. Portion size effects on daily energy intake in low-income Hispanic and African American children and their mothers. Am J Clin Nutr. 2007:86(6):1709-16.

8. Birch LL, Savage JS, Fisher JO. Right sizing prevention. Food portion size effects on children's eating and weight. Appetite. 2015;88:11-6.

9. Burger KS, Kern M, Coleman KJ. Characteristics of self-selected portion size in young adults. J Am Diet Assoc. 2007;107(4):611-8.

10. Croker H, Sweetman C, Cooke L. Mothers' views on portion sizes for children. J Hum Nutr Diet. 2009;22(5):437-43.

11. Sherry B, et al. Attitudes, practices, and concerns about child feeding and child weight status among socioeconomically diverse white, Hispanic, and African-American mothers. J Am Diet Assoc. 2004;104(2):215-21.

12. Malik VS, et al. Sugar-sweetened beverages and weight gain in children and adults: a systematic review and meta-analysis. Am J Clin Nutr. 2013:98(4):1084-102.

13. DeBoer MD, Scharf RJ, Demmer RT. Sugar-sweetened beverages and weight gain in 2-to 5-year-old children. Pediatrics. 2013;132(3):413-20.

14. The Swiss Society of Nutrition. 2016. http://www.sge-ssn.ch/fr/toi-et-moi/ boire-et-manger/aux-differents-ages/enfance/. Accessed 19 Apr 2016.

15. Briefel R, et al. The 2008 Feeding Infants and Toddlers Study (FITS): parents' perceptions and practices related to diet and weight. FASEB J. 2011;25(1):99-102.

16. Hoare A, et al. A qualitative study of the factors that influence mothers when choosing drinks for their young children. BMC Res Notes. 2014;7:430-9.

17. Beck AL, et al. Understanding How Latino parents choose beverages to serve to infants and toddlers. Matern Child Health J. 2013;18(6):1308-5.

18. Guba EG, Lincoln YS. Competing paradigms in qualitative research. In: Denzin NK, Lincoln YS, editors. Handbook of qualitative research. Thousand Oaks: Sage; 1994. p. 105-17.

19. Furst $T$, et al. Food choice: a conceptual model of the process. Appetite. 1996:26(3):247-66.

20. Sobal J, Bisogni CA. Constructing food choice decisions. Ann Behav Med. 2009:38(1):37-46.

21. Braun V, Clarke V. Successful qualitative research: a practical guide for beginners. 1st ed. London: Sage; 2013.

22. Birch LL, et al. Confirmatory factor analysis of the child feeding questionnaire: a measure of parental attitudes, beliefs and practices about child feeding and obesity proneness. Appetite. 2001;36(3):201-10.

23. Braun V, Clarke V. Using thematic analysis in psychology. Qual Res Psychol. 2006;3(2):77-101.

24. Herman AN, et al. A qualitative study of the aspirations and challenges of low-income mothers in feeding their preschool-aged children. Int J Behav Nutr Phys Act. 2012;9:1.

25. Carnell $\mathrm{S}$, et al. Parental feeding behaviours and motivations. A qualitative study in mothers of UK pre-schoolers. Appetite. 2011;57(3):665-73.

26. Hart LM, et al. What parents know and want to learn about healthy eating and body image in preschool children: a triangulated qualitative study with parents and early childhood professionals. BMC Public Health. 2015;15:1.

27. Suggs LS. Low adherence of Swiss children to national dietary guidelines. Prev Med Rep. 2016:3:244-9.

28. Abreu D, et al. Compliance with the swiss society for Nutrition's dietary recommendations in the population of Geneva, Switzerland: a 10-year trend study (1999-2009). J Acad Nutr Diet. 2014;114:774-80.

29. Furst T, et al. Food classifications: levels and categories. Ecol Food Nutr. 2000;39(5):331-55.

30. Sobal J, et al. A conceptual model of the food choice process over the life course. In: Shepherd R, Raats M, editors. The Psychology of Food Choice. Wallingford: $\mathrm{CABl} ; 2006$. p. 1-18.

31. Polanyi M. Tacit knowledge, Knowledge in organizations. 1997. p. 135-46.

32. Johnson $\mathrm{SL}$, et al. Getting my child to eat the right amount: mothers' considerations when deciding how much food to offer their child at a meal. Appetite. 2014;88:4-32

33. Gupte S, Anderson E, Anderson L. Constipation. In: Gupte S, editor. Pediatric Gastroenterology, Hepatology and Nutrition, Recent Advances in Pediatrics: Pediatric Gastroenterology, Hepatology and Nutrition. New Delhi: Jaypee; 2013. p. 133-47.

34. Bucher T. Siegrist M. Children's and parents' health perception of different soft drinks. Br J Nutr. 2015;113(3):26-535. 
35. Bauer KW, et al. Parental employment and work-family stress: associations with family food environments. Soc Sci Med. 2012;753:496-504.

36. de IA A, et al. To cook or not to cook: a means-end study of motives for choice of meal solutions. Food Qual Pref. 2007;18(1):77-88.

37. Geeroms N, Verbeke W, Van Kenhove P. Consumers' health-related motive orientations and ready meal consumption behaviour. Appetite. 2008:51(3):704-12.

38. Moisio R, Arnould EJ, Price L. Between mothers and markets constructing family identity through homemade food. J Consum Cult. 2004;4(3):361-84.

39. Drewnowski A, Specter S. Poverty and obesity: the role of energy density and energy costs. Am J Clin Nutr. 2004;79(1):6-16.

40. Khalatbari-Soltani S, Marques-Vidal P. Not as bad as you think: a comparison of the nutrient content of best price and brand name food products in Switzerland. Prev Med Rep. 2016;3:222-8.

41. Tong A, Sainsbury P, Craig J. Consolidated criteria for reporting qualitative research (COREQ): a 32-item checklist for interviews and focus-groups. Int J Qual Health Care. 2007;19(6):49-57.

42. L'Assemblée fédérale de la Confédération suisse, Loi fédérale relative à la recherche sur l'être humain. In: Le Conseil Federal, Le portail du governement Suisse. 2011. https://www.admin.ch/opc/fr/federal-gazette/ 2011/6823.pdf. Accessed 2 May 2016.

\section{Submit your next manuscript to BioMed Central and we will help you at every step:}

- We accept pre-submission inquiries

- Our selector tool helps you to find the most relevant journal

- We provide round the clock customer support

- Convenient online submission

- Thorough peer review

- Inclusion in PubMed and all major indexing services

- Maximum visibility for your research

Submit your manuscript at www.biomedcentral.com/submit 